\title{
Damage Characterization of Polypropylene Honeycomb Sandwich Panels Subjected to Low-Velocity Impact
}

\author{
Freeda A. Amir, ${ }^{1}$ A. R. Othman, ${ }^{1}$ and H. Md. Akil ${ }^{2}$ \\ ${ }^{1}$ School of Mechanical Engineering, Universiti Sains Malaysia, 14300 Nibong Tebal, Pulau Pinang, Malaysia \\ ${ }^{2}$ School of Materials and Mineral Resources Engineering, Universiti Sains Malaysia, 14300 Nibong Tebal, Pulau Pinang, Malaysia
}

Correspondence should be addressed to A. R. Othman; merahim@eng.usm.my

Received 15 July 2013; Revised 2 October 2013; Accepted 2 October 2013

Academic Editor: John W. Gillespie

Copyright (C) 2013 Freeda A. Amir et al. This is an open access article distributed under the Creative Commons Attribution License, which permits unrestricted use, distribution, and reproduction in any medium, provided the original work is properly cited.

\begin{abstract}
The post-test deformation and failures of sandwich composites may involve complex interactions between various failure mechanisms. In this study, the extent of impact damages and response of the thermoplastic honeycomb sandwich are analysed through energy profile diagrams and associated load history curves. The degree of the postimpact damages of the sandwich is further characterized using an optical surfaces metrology analysis. The thickness of the honeycomb was found to influence the extent of the damage which occurred following the low-velocity impact. Thicker core was able to sustain a higher load as well as the energy absorption before total failure occurred.
\end{abstract}

\section{Introduction}

Sandwich composites are increasingly used in load bearing structures due to the fact that the sandwich construction is capable in providing an improved bending rigidity without significant increase in structural weight. The structural concept is analogous to an I-beam; the stiff polymer composite skins are comparable to flanges, which carry axial and bending loads, with one skin in compression and the other in tension. On the other hand, the core corresponds to the web, which primarily resists the shear loads. However, there is a concern on the ability of the structure particularly the polymer sandwich composite to withstand impact loading during the in-service operations since a reduction in stiffness and residual strength may occur following the occurrence of failures.

The deformation and failures of sandwich composites involve inelastic behavior of the constituent materials and complex interactions between the various failure mechanisms. Abrate [1] has identified five different failure modes during low-velocity impact, namely, core buckling, delamination in the skin, core cracking, and matrix cracking, and fiber breakage. On the other hand, Mines and Jones [2] classified up to eight possible modes of failure for sandwich panels, including upper skin wrinkling, upper skin compression failure, lower skin tensile failure, and core shear. The first three modes were observed in thin-skinned and large-spanned panels, while for thick-skinned and short-spanned panels, the last failure mode was the most likely. Besant et al. [3] also outlined three potential mechanisms that could occur during low-velocity impact of honeycomb sandwich. If the core is crushed locally with the skin remaining intact, a permanent visible indentation is produced. If the adhesive bond between skin and core is weak, the relatively stiff skin would spring back after impact, breaking the bond and leaving the crushed core hidden underneath. The final case occurs when the force produces high through-thickness shear in the skin, causing local delaminations.

In general, eight parameters could be identified from the available literatures [1,3-19] to influence different failure mechanisms of the structures under loads: chemical and mechanical properties of the constituents of the skin, core and adhesive bond; stacking sequence of composite skins; skin and core thicknesses; geometrical dimension; loading rate; boundary conditions; impactor shape; and energy applied during the test. Combination of these parameters may result in a number of failure modes, which then determine the amount of energy dissipated. A number of authors have also 
considered in particular the influence of geometrical configuration of the core on the response of sandwich composites. Petras and Sutcliffe [16] found in both quasi-static and low-velocity impact loadings that the thickness of the core played a role in controlling the sequence in which failures occurred and predominated. However, at higher velocity, this contribution becomes less significant. Zenkert [17] reported that an increase in thickness of the honeycomb core gave an increase in specific total energy. The increase is attributed to the delay of the start of plastic deformation, offering a substantial increase in ultimate and crushing strengths. The effect of instability in the structure after collapse could also be reduced by using a core with larger thickness. However, higher core thickness tends to increase the possibility of debonding between the skin and core of the sandwich panel $[14,15,18,19]$. In contrast, Othman and Barton [20] proposed that the thickness of the honeycomb core provides little effect on the overall energy-absorbing capacity of the sandwich composite, with the out-of-plane compressive and shear strengths of honeycomb being generally independent of the height. On the same notes, Paik et al. [4] found that the core height is an insignificant parameter on the overall crushing response of the structure; but increasing the height preserved a longer load plateau before densification took place.

To some extent, several researchers have developed systematic analysis techniques to help in characterizing the degree of failure modes at different levels of composite structures. Akil Hazizan and Cantwell [15] have utilized a simple energy-balance model which is based on the dissipation of the incident energy of the projectile during impact to predict the low-velocity impact response of honeycomb sandwich structure. On the other hand, Choi [21] has proposed a "lumped mass method" and a spring element method to approximately calculate the contact force history on composite sandwich plates subjected to low-velocity impact. Significantly, Aktąs et al. [22] has considered energy profile diagrams and associated load-deflection curves on impact response of unidirectional glass/epoxy laminates. It was found that for lower impact energies, the main damage modes include delamination and matrix cracks.

In this study, the extent of impact damages on the thermoplastic honeycomb sandwich is analyzed. The sandwich beams were prepared with three different core thicknesses and were subsequently subjected to low-velocity impact at different energy levels. The impact response of the sandwich was determined through energy profile diagrams and associated load history curves, in which the sequences of the damages were examined. The degree of the postimpact damages of the sandwich has been further characterized using an optical surfaces metrology analysis.

\section{Experimental Materials and Methods}

2.1. Materials Preparation. Details of the constituent materials used in the construction of honeycomb sandwich panels are described in Table 1. The composite skins of the sandwich were fabricated from the plain weave fabric of E-glass fiber with epoxy resin using a wet lay-up process. The skin was prepared using 7 plies of the fabric with the stacking
TABLE 1: Specification of the core.

\begin{tabular}{lcc}
\hline Component & Material & Specification \\
\hline Core & $\begin{array}{c}\text { Polypropylene } \\
(\mathrm{pp}) \text { honeycomb }-8 \mathrm{~mm}\end{array}$ & $\begin{array}{c}\text { Tissue }-40 \mathrm{~g} / \mathrm{m}^{2} \\
\text { Weight }-80-90 \mathrm{kgs} / \mathrm{m}^{3} \\
\text { Thickness }-20 \mathrm{~mm}, 40 \mathrm{~mm} \\
\text { and } 60 \mathrm{~mm}\end{array}$ \\
\hline Facings & $\begin{array}{c}\text { E-glass woven } \\
\text { fabric }\end{array}$ & Plain weave \\
\hline Adhesive & Epoxy resin & - \\
\hline
\end{tabular}

sequence of $[(0.90) /( \pm 45)]$, resulting in $1.64 \mathrm{~mm}$ thick. A two-part epoxy resin was used with the mixing ratio of $2: 1$ (Resin (A): Hardener (B)). The resin contains the main compound of diglycidyl ether of bisphenol-F, providing a low viscosity property that enables the material to react with a full range of epoxy curatives. The key characteristics of a room temperature curing of the wet lay-up system are low viscosity, adequate pot life, and reactivity. The laminates were subsequently postcured at $80^{\circ} \mathrm{C}$ for 2 hours.

The polypropylene honeycomb core was supplied by Qingdao Polycore Technology Co. Ltd., with both sides laminated with nonwoven polyester tissue of $40 \mathrm{~g} / \mathrm{m}^{2}$ as shown in Figure 1. The polyester allows better bonding of the honeycomb core to the composite skins. Three core thicknesses were used for the study: $20 \mathrm{~mm}, 40 \mathrm{~mm}$, and $60 \mathrm{~mm}$. Subsequently, the sandwich panels were prepared through secondary bonding process using a hydraulic hot press, in which the liquid epoxy resin was utilized as bonding mechanism between the skin and core. The sandwich was cured at $60^{\circ} \mathrm{C}$ for 10 minutes. The final thicknesses of the sandwich samples were approximately $23.28 \mathrm{~mm}, 43.28 \mathrm{~mm}$, and $63.28 \mathrm{~mm}$, respectively, with the in-plane area of $210 \mathrm{~mm} \times 70 \mathrm{~mm}$.

2.2. Low-Velocity Impact Test. Low-velocity impact test was carried out using an instrumented drop weight impact testing machine as shown in Figure 2. The instrument was equipped with a data acquisition system of V.6.0 DEWESoft to continuously attain the impact force and time. Using this machine, the impact energy and velocity can be varied by changing the mass and height of the weight. A total impactor mass of $6.1 \mathrm{~kg}$ was used with drop heights of $0.25 \mathrm{~m}, 0.50 \mathrm{~m}$, and $0.75 \mathrm{~m}$ giving the impact velocity of $9.81 \mathrm{~m} / \mathrm{s}$ and impact kinetic energies (IKE) of $15 \mathrm{~J}, 30 \mathrm{~J}$, and $45 \mathrm{~J}$.

In addition, a high speed video camera of Olympus iSpeed 2 was used to record the details of deformation and failure sequences of the structure with the processor capable of recording at rates up to 5000 frames per second. In the present study, sequences of the crushing process were captured to enable continuous identification of the material response as well as the impactor displacement. The start of the deflection histories was subsequently synchronized with the initiation of the load obtained from the load cell.

2.3. Optical Surfaces Analysis. The failure analysis of the damage structure was analyzed using Infinite Focus Alicona Microscope as shown in Figure 3. Prior to the analysis, images 


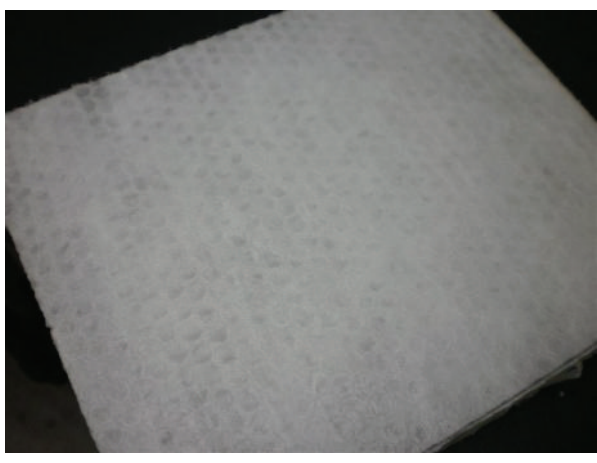

(a)

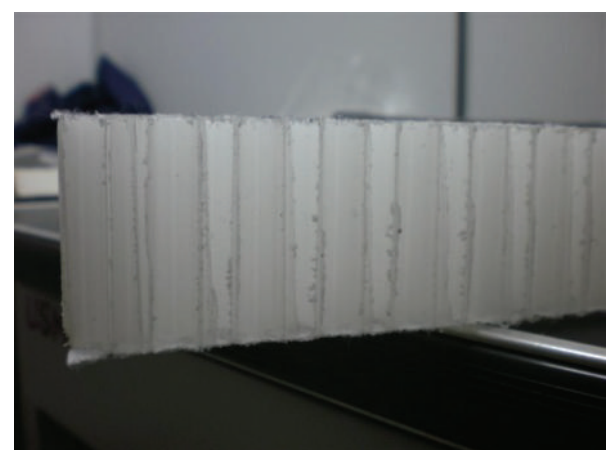

(b)

FIgure 1: Polypropylene honeycomb core in (a) top view and (b) side view.

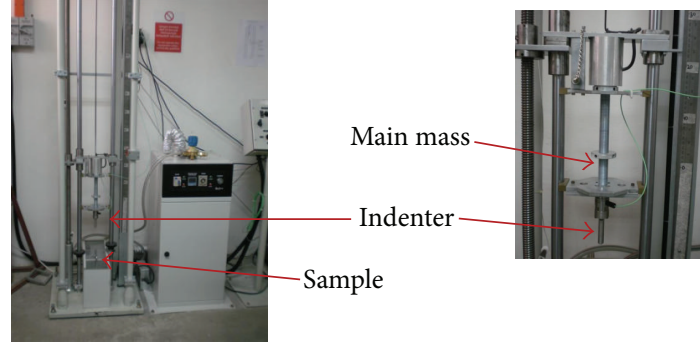

FIGURE 2: Drop weight impact testing machine.

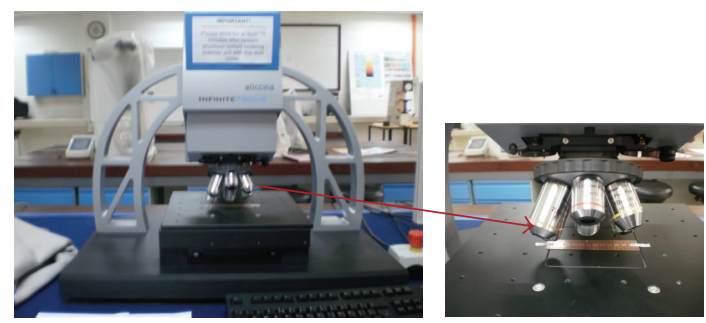

Figure 3: Infinite Focus Alicona.

of the damage were captured using a Nikon SLR D90 digital camera. A 3D surface profile was created by superimposing successive focal planes comprising the specimen's surface. A 2D image analysis was developed, followed by 3D image analysis in order to obtain a complete contour surface image. Subsequently, a profile analysis was carried out to determine the indentation depth and the damage area of the samples.

\section{Results and Discussion}

3.1. Load and Energy Profiles. Figure 4 indicates the loadtime history plots for different impact energies at specific core thicknesses of $20 \mathrm{~mm}, 40 \mathrm{~mm}$, and $60 \mathrm{~mm}$. For the $20 \mathrm{~mm}$ and $60 \mathrm{~mm}$ core, the results demonstrated significant difference on the response with different impact energies; however, the $40 \mathrm{~mm}$ honeycomb suffered similar load profiles even for different impact energies which are applied. From the observation, Figures 4(a) and 4(b) show slightly similar ultimate loads, achieved for those $20 \mathrm{~mm}$ and $40 \mathrm{~mm}$ core thicknesses which exhibited the same impact loading that the panels could sustain, reflecting the strength and stiffness of a particular core thickness. On the other hand, for the highest core thickness of $60 \mathrm{~mm}$, a substantial increase in the ultimate load before failure was demonstrated, as the sandwich possesses higher stiffness and toughness due to the difference in thickness.

Interestingly, at higher impact energy (i.e., $45 \mathrm{~J}$ ), longer response has been observed particularly for $20 \mathrm{~mm}$ and $60 \mathrm{~mm}$ honeycomb sandwiches, in which the panels were capable to sustain longer period of loading, resulting in perhaps higher energy absorption. This might be attributed to the pronounced global bending deformation of the panels with the increase in the impact velocities.

In order to better clarify the effect of the core thickness on the load profiles, the results were further plotted for the different thicknesses at the particular impact intensity as shown in Figure 5. For all the tested specimens, sharp load drops were evidently observed in the transient load response curves; those were attributed to a qualitative indication of significant damages. A localized damage occurring within the energy levels could be visualized through the change in the slope of the load-time curves.

Figure 5(a) summarizes the impact responses with regard to the load profiles for three different core thicknesses subjected to $15 \mathrm{~J}$ of IKE. The first load drop depicted from the curve indicated the top skin failure at the impacted region. As a result of the failure, it subsequently enabled the penetration through the honeycomb core, causing lower skin failure for those shorter core heights. At $15 \mathrm{~J}$, the overall profiles were mostly dominated by elastic response, which is a function of structural stiffness. Lower portion of the skin was found to fail in tension allowing the impactor to penetrate through its thickness. In addition, the woven nature of the fabric also offered a significant resistance to the breakage of the fibres.

For $40 \mathrm{~mm}$ and $60 \mathrm{~mm}$ samples (i.e., Figures 5(b) and 5(c)), the localized indentation was found on the upper skin, as well as the partial penetration of the honeycomb core. Thus, lower skin was invisible to the impact damage. It was seen that the load-time curves exhibited almost identical information on the response of sandwiches for impact energies $30 \mathrm{~J}$ and $45 \mathrm{~J}$. In addition, in the case of higher impact energies (30 J and $45 \mathrm{~J}$ ), the impact responses were influenced 


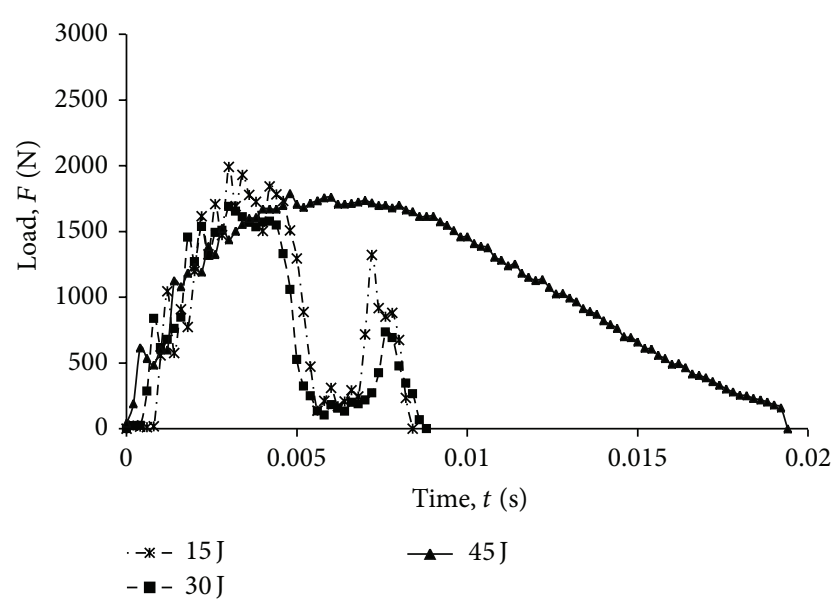

(a)

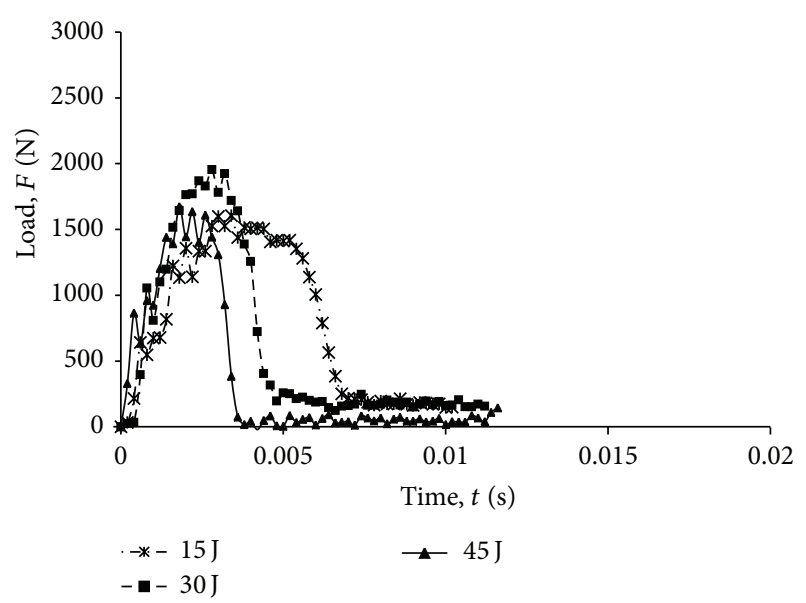

(b)

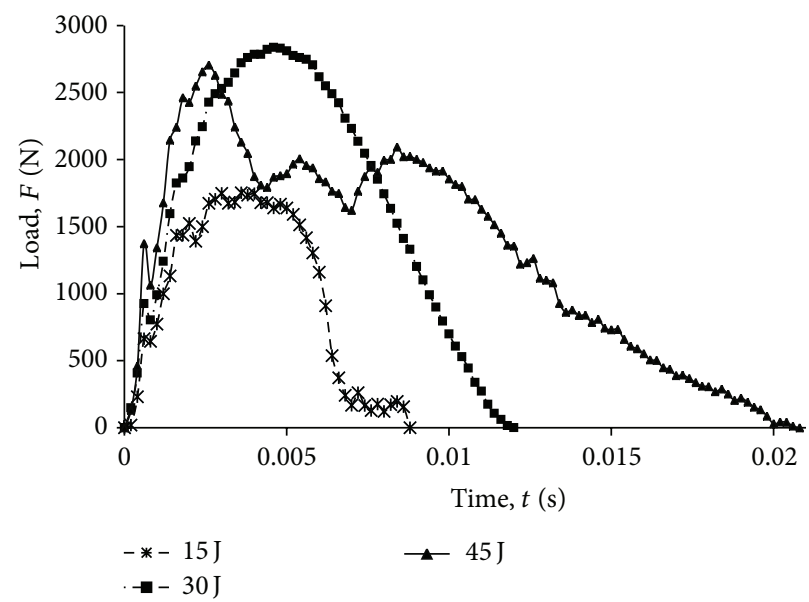

(c)

Figure 4: Load versus time plots for sandwich panels with different thicknesses (a) $20 \mathrm{~mm}$, (b) $40 \mathrm{~mm}$, and (c) $60 \mathrm{~mm}$ subjected to different impact energies.

by the state of damages rather than the elastic response of the samples. As the energy level was higher, there were considerable damages in the samples especially at the upper skin. The amounts of absorbed energy were measured for the perforation of both the upper and lower skins. Therefore, major core crushing involved and appeared at samples as well as the penetration through the thickness of the core. The area underneath the damage region of the upper skin suffered significant broken cells and several folds of crumpled zone were observed. Following the failure, the load was found to increase again and this was corresponded to the crushing of core together with lengthening of cracks in the upper skin. It could be concluded that most of the impact energy has been absorbed through the upper skin indentation at the point of impact and core damage beneath the upper skin.

Figure 6 shows several key images of the impact event captured using the high speed camera. Based on the series of the images, the damage sequences as well as the material deformation could be identified and subsequently associated with the respective time-dependent energy profiles. In addition, Figure 7 indicates the energy-time curve of the sandwich panels subjected to IKE of $15 \mathrm{~J}$. However, different core thicknesses at different impact energies provided dissimilar trend for energy response of time-dependent profile. At $15 \mathrm{~J}$ of impact energy, the highest energy absorbed was observed at $20 \mathrm{~mm}$ of thermoplastic core thickness.

On the other hand, Figure 8 specifies the energy-time curve of the sandwich panels impacted at $30 \mathrm{~J}$. The abrupt change in the curve gradient indicated the change in the failure formation, starting from upper skin failure to lower skin perforation. At point 1, failure of indentation for the upper skin was observed. As the impact loading has been increased, the distinctive damages on the upper skin such as fiber rupture, matrix cracking were apparent up to point 2. Simultaneously, the core only experienced elastic deformation. At this point (point 2), damages have reached the last plies of the upper skin, where the sudden change in the gradient of the curve attributed to the start of the plastic deformation of the thermoplastic core due to the change in the stiffness. The change from higher stiffness of the skin to relatively lower stiffness of the honeycomb could cause core crushing to occur underneath the damage region of the upper skin. 


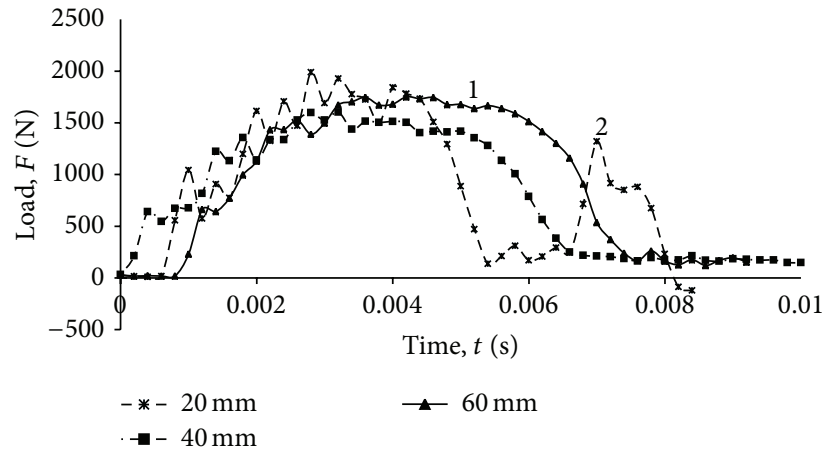

(a)

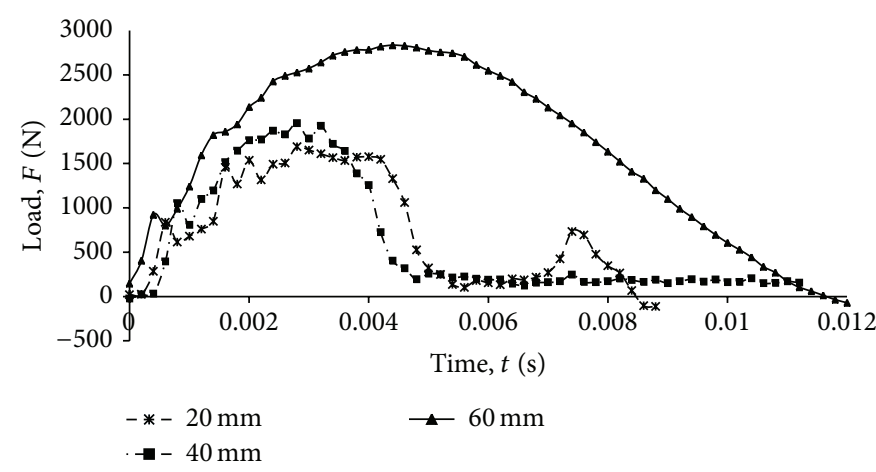

(b)

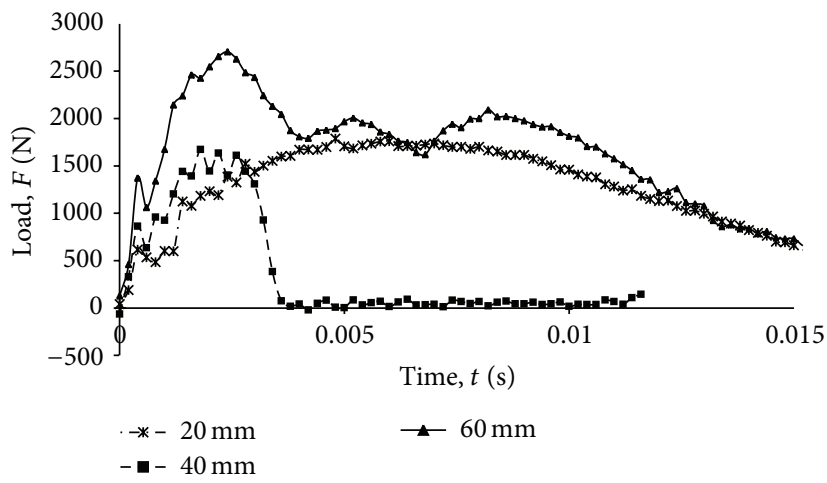

(c)

Figure 5: Load versus time plots for sandwich panels subjected to (a) $15 \mathrm{~J}$, (b) $30 \mathrm{~J}$, and (c) $45 \mathrm{~J}$ of impact energies. Point 1: upper skin failure; point 2: penetration at impact region.
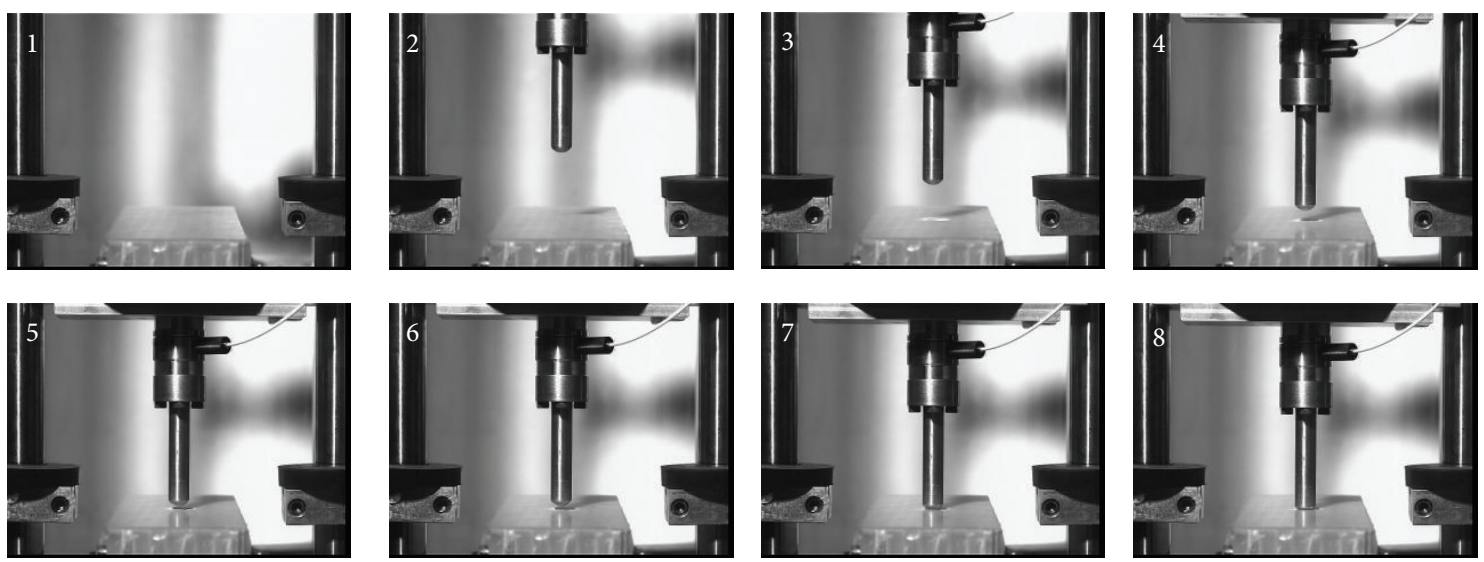

FIGURE 6: The impact sequences of the sandwich composites taken from the high speed video camera.

Upon reaching point 3 , the dominant core failures such as core crushing and buckling have been observed with severe perforation at the lower composite skin.

Similar trends and responses were observed for different impact energies as shown in Figure 9. However, at $45 \mathrm{~J}$ of impact energy, the response was observed rather differently than that of $15 \mathrm{~J}$, as the impact energy was mostly absorbed for the core thickness of $60 \mathrm{~mm}$. As the thickness of the core increased, the duration taken to complete the impact has prolonged with greater extent of deformation, thus contributed to higher energy absorption.

On the other hand, Figure 10 summarizes the maximum load recorded on the sandwich beams subjected to three IKE levels. At $15 \mathrm{~J}$ of impact loading, similar responses were observed for those sandwich beams regardless their difference in the core thickness. As the IKE levels have increased to $30 \mathrm{~J}$ and $45 \mathrm{~J}$, sandwich panel with $60 \mathrm{~mm}$ core thickness experienced the highest maximum load. 


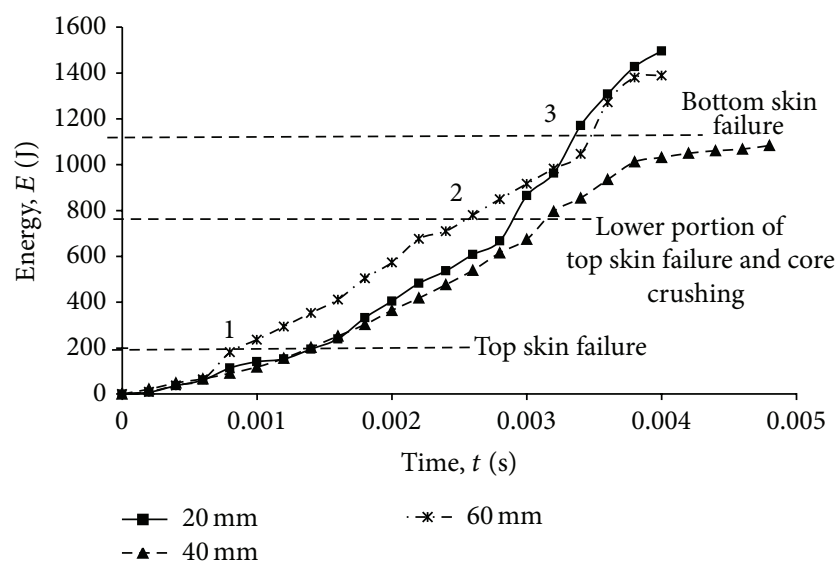

Figure 7: Energy profile diagram for the sandwich composite subjected to $15 \mathrm{~J}$ of impact energy.

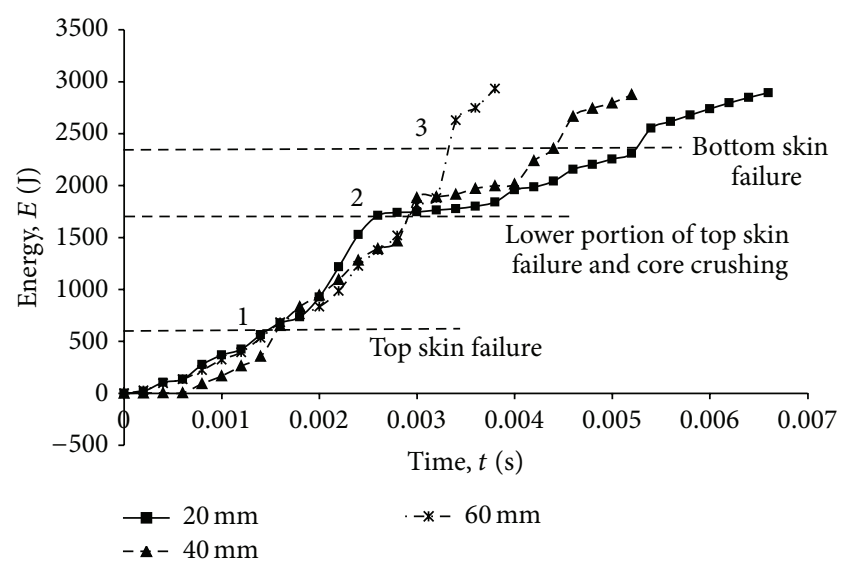

FIGURE 8: Energy profile diagram for the sandwich composite subjected to $30 \mathrm{~J}$ of impact energy.

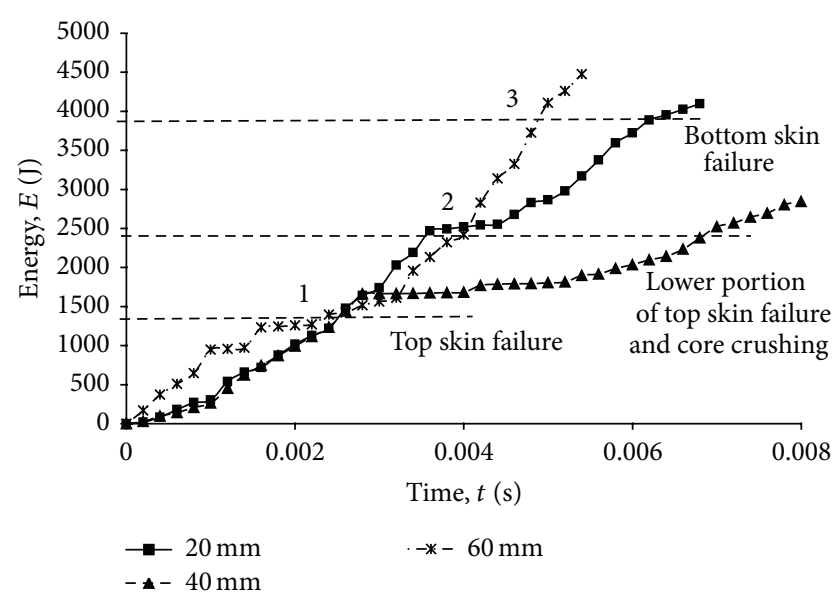

FIgURE 9: Energy profile diagram for the sandwich composite subjected to $45 \mathrm{~J}$ of impact energy.

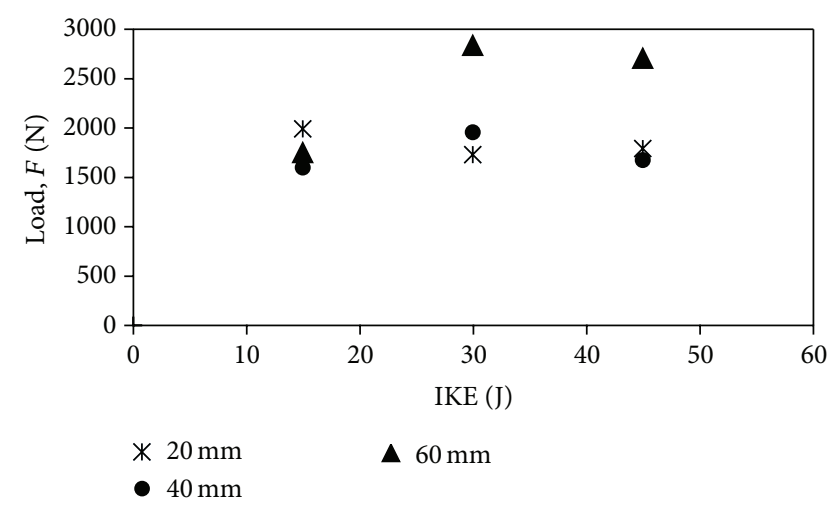

Figure 10: Maximum load recorded on the sandwich beams subjected to three IKE levels.

The thicker cores were able to sustain more impact load with the elastic buckling being more pronounced prior to the failure.

3.2. Impact Damage Characterization Analysis. The postimpact damages of the sandwich beams have been analyzed in detail, in which the impacted surfaces, the cross-sectional area and the surface metrology of the beams have been examined. Figures 11, 12, and 13 show the postimpact analysis of the damage areas of the sandwich beams subjected to impact energy at $15 \mathrm{~J}, 30 \mathrm{~J}$, and $45 \mathrm{~J}$, respectively. Generally, the damages have initiated from the local indentation on the upper skin, followed by core crushing with multiple plastic folds of the honeycomb cell wall and continued by lower skin failure of skin-core debonding and skin perforation.

3.3. Impacted Surface-Upper Composite Skin. These impacted surfaces resulted not only in localized indentation and fracture of the top skin, but also notably in the interskin delamination. The failures may initiate from the extent of microdamages of fiber/matrix microcracking or interply delamination in the upper skin prior to the failure. In fact, the upper skin has greatly contributed to the stability of the sandwich panels and failure mechanism. It was found that none of the panels has survived from the impact failures, and all the impacted upper skins failed for all impact energy levels.

3.4. Cross-Sectional Area-Honeycomb Core. The PP thermoplastic honeycomb core played an important role in progressively controlling the sequences in which total failure mechanisms occurred and predominated. At $15 \mathrm{~J}$ of impact energy, plastic folding mechanisms were observed for the core thickness of $20 \mathrm{~mm}$. Multiple core damages of cell crushing, wrinkling and buckling have dominated the response. Moreover, the perforation of upper skin has contributed to delamination of the skin and debonding of the skin-core interphase. For core thicknesses of $40 \mathrm{~mm}$ and $60 \mathrm{~mm}$, major failures only occurred at the top region of the sandwich structure, in which the local indentation might lead to skin perforation and minimal core crushing. 

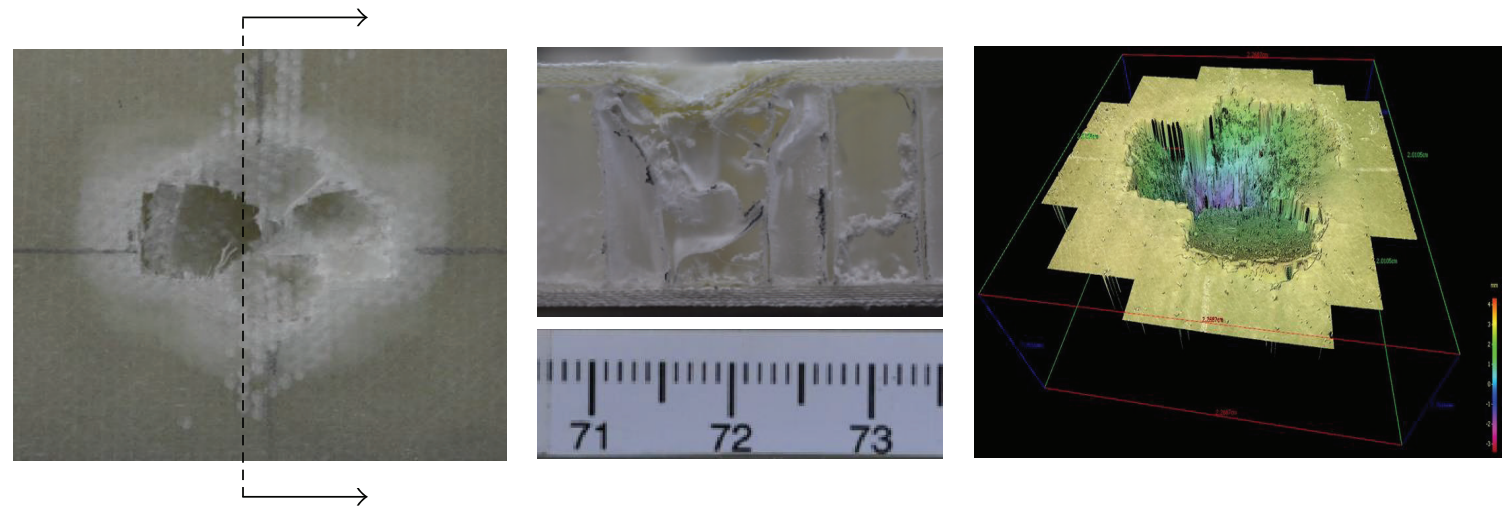

(a) Core thickness of $20 \mathrm{~mm}$
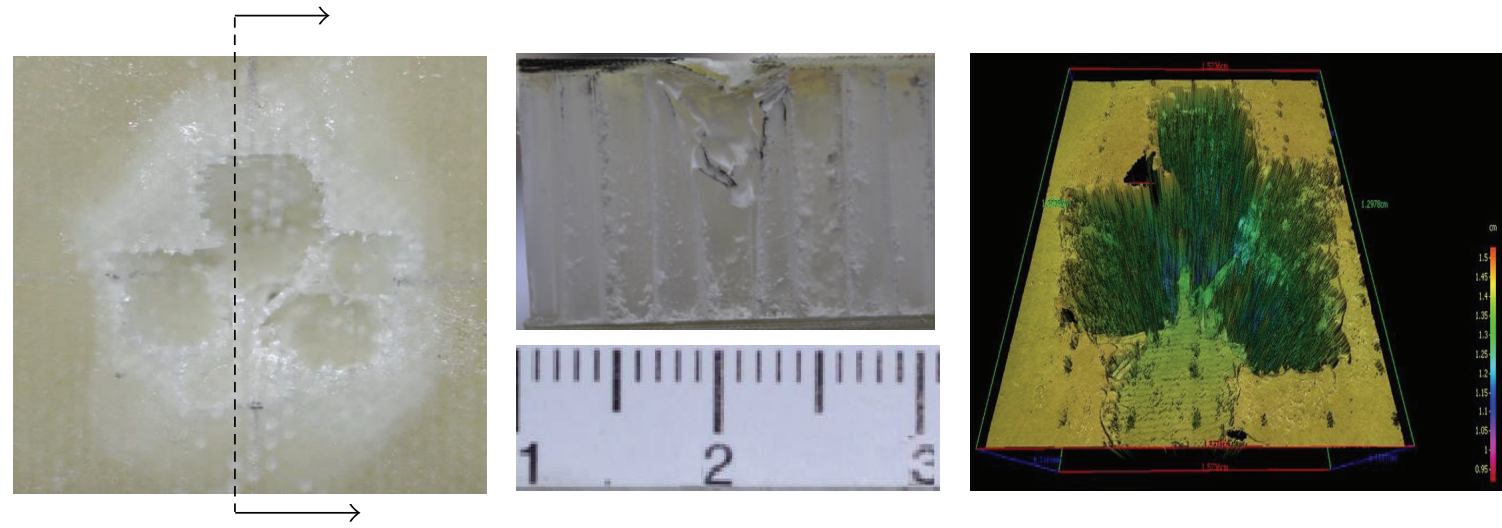

(b) Core thickness of $40 \mathrm{~mm}$
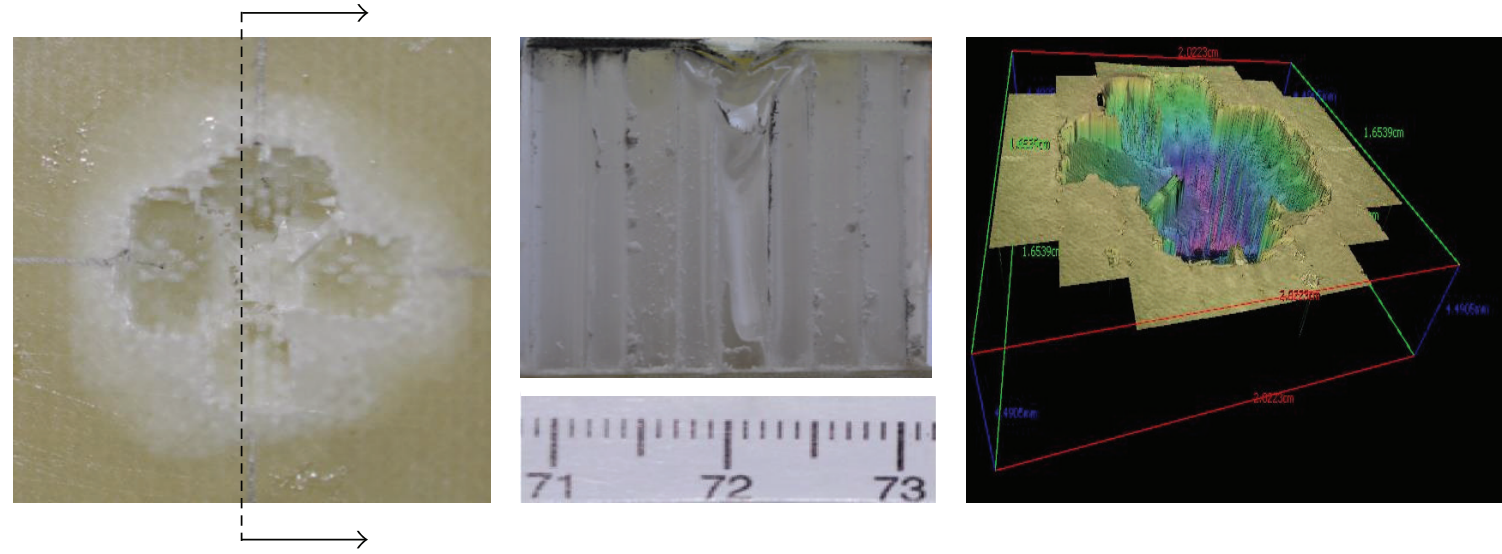

(c) Core thickness of $60 \mathrm{~mm}$

FIGURE 11: Impacted surfaces, cross-sectional views, and optical surface metrology of the sandwiches subjected to $15 \mathrm{~J}$ of IKE.

However, at $30 \mathrm{~J}$ of impact kinetic energy (IKE), more prominent damages were observed for the delamination at the lower composite skin especially for the thinner core thickness. Debonding of the skin-core interphase was crucial for this thickness $(20 \mathrm{~mm})$ compared to the counterpart panels $(40 \mathrm{~mm}$ and $60 \mathrm{~mm}$ ) where no significant failure was observed except only on the top surface of the structure.

On the other hand, at $45 \mathrm{~J}$ of impact kinetic energy (IKE), a substantial perforation of the lower skin was observed as clearly shown in Figure 13(a) particularly for core thickness of $20 \mathrm{~mm}$. Severe penetrations through the lower skin have been identified due to higher impact loading, notably for the specimens with thinner cores. Simultaneously, core crushing has also occurred at this level of impact loading. Also, minor failures for those sandwiches with core thickness of $40 \mathrm{~mm}$ and $60 \mathrm{~mm}$ were observed where there the upper skin failures were dominant, leading to the skin-core debonding and minor core crushing.

It was clearly shown that, for thinner samples, impactor tended to penetrate the whole thickness which caused total core crushing or total core failure. In contrast, only partial core crushing has been observed for thicker samples at the 

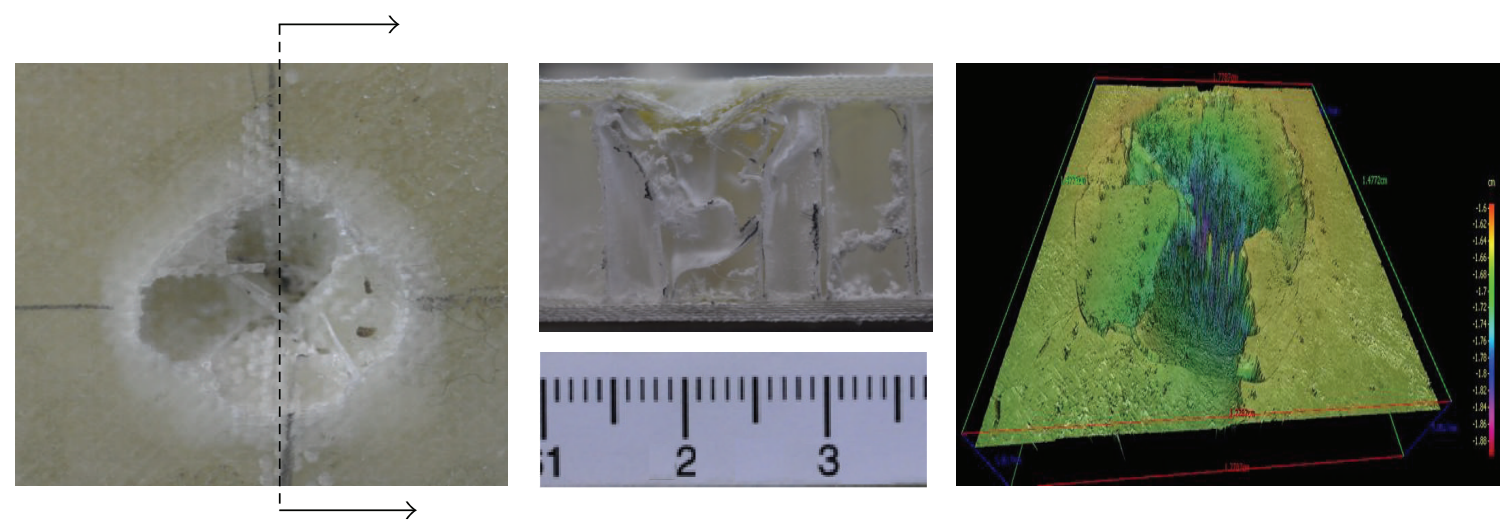

(a) Core thickness of $20 \mathrm{~mm}$
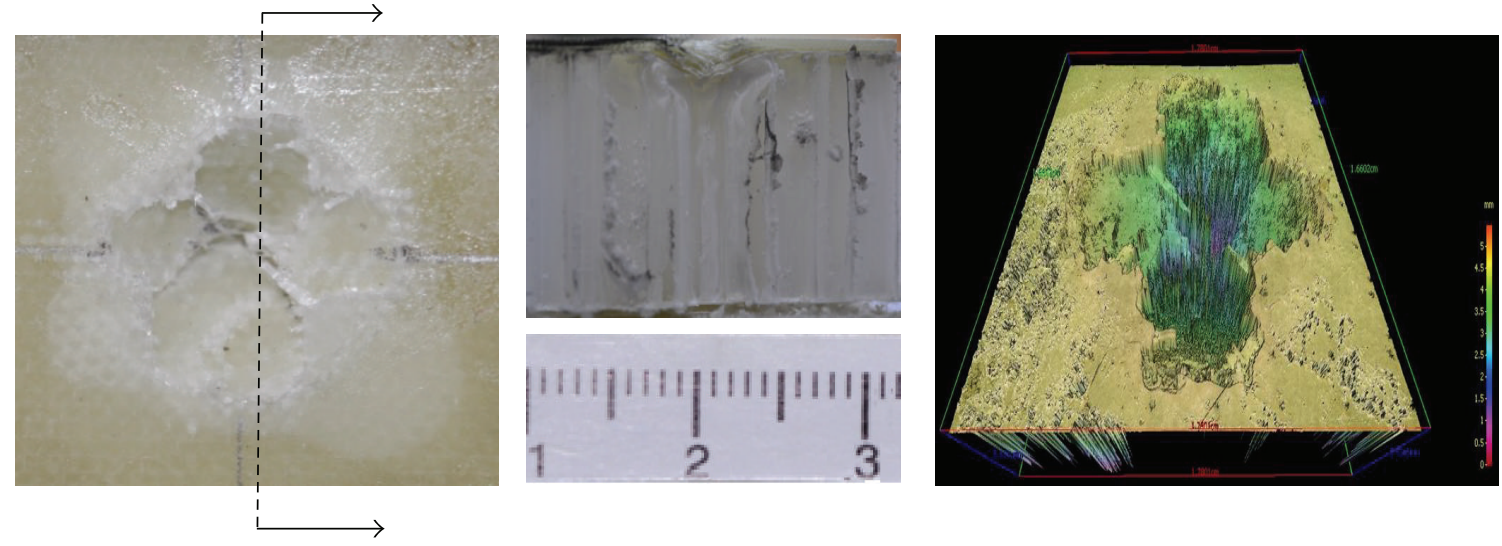

(b) Core thickness of $40 \mathrm{~mm}$
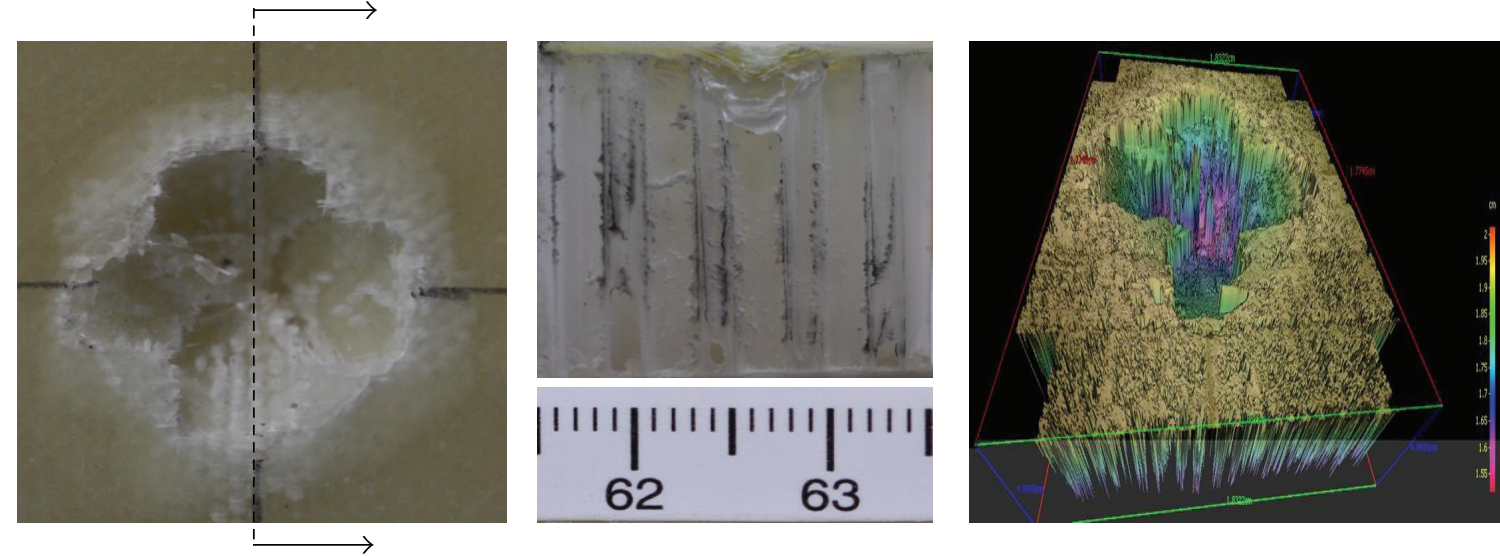

(c) Core thickness of $60 \mathrm{~mm}$

FIGURE 12: Impacted surfaces, cross-sectional views, and optical surface metrology of the sandwiches subjected to $30 \mathrm{~J}$ of IKE.

same impact energy. Thicker honeycomb provides higher rigidity and stability of the sandwich, which then offer higher resistance to out-of-plane deformation and may significantly influence the extent and severity of the damages following the impact.

\subsection{Surface Metrology - Indentation Depth and Damage Area.} Through the optical microscopic examination, 2D and 3D contour images of the indentation failure have be obtained, which provided the exact indentation depth and damage area.
As shown in Table 2, the indentation area was found almost identical for each thickness and impact loading. This was due to the same diameter of the indenter used throughout the experimental work. In addition, for core thickness of $60 \mathrm{~mm}$, it was clearly seen that the indentation depths have increased as the impact energy increased. On the other hand, for the sandwich with core thicknesses of $20 \mathrm{~mm}$ and $40 \mathrm{~mm}$, a significant difference was observed between the readings for different impact loadings. Although the indentation depth was considered high between the loadings, the difference 

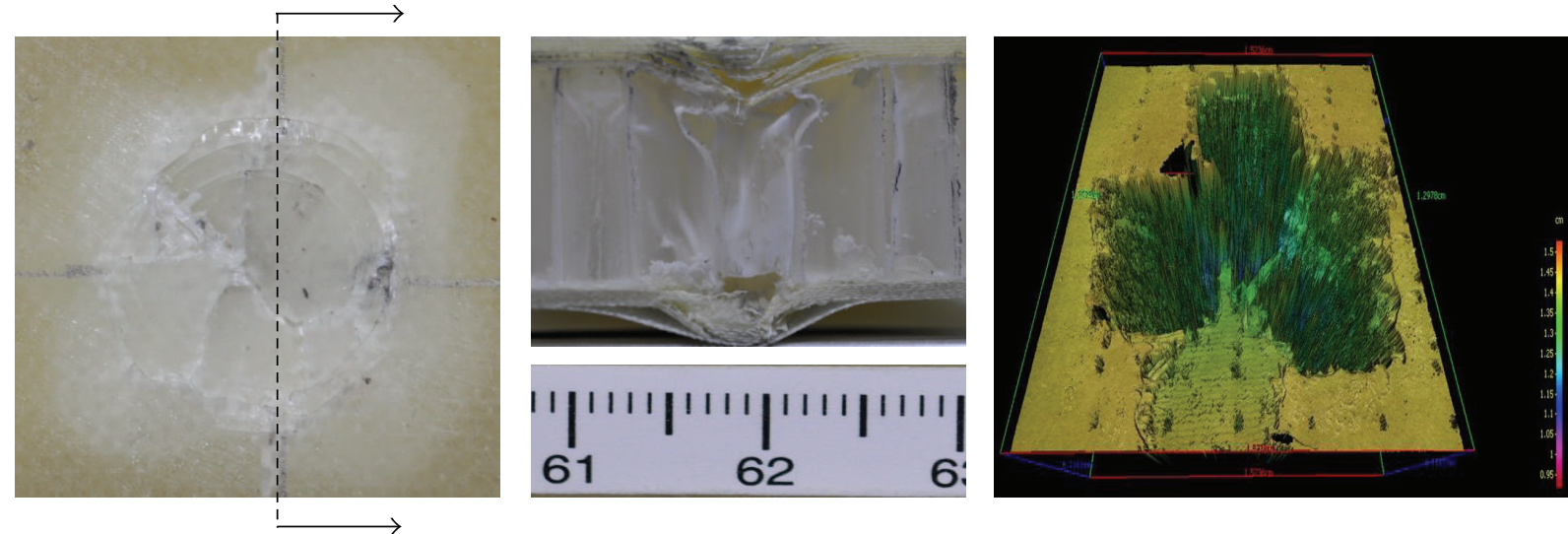

(a) Core thickness of $20 \mathrm{~mm}$
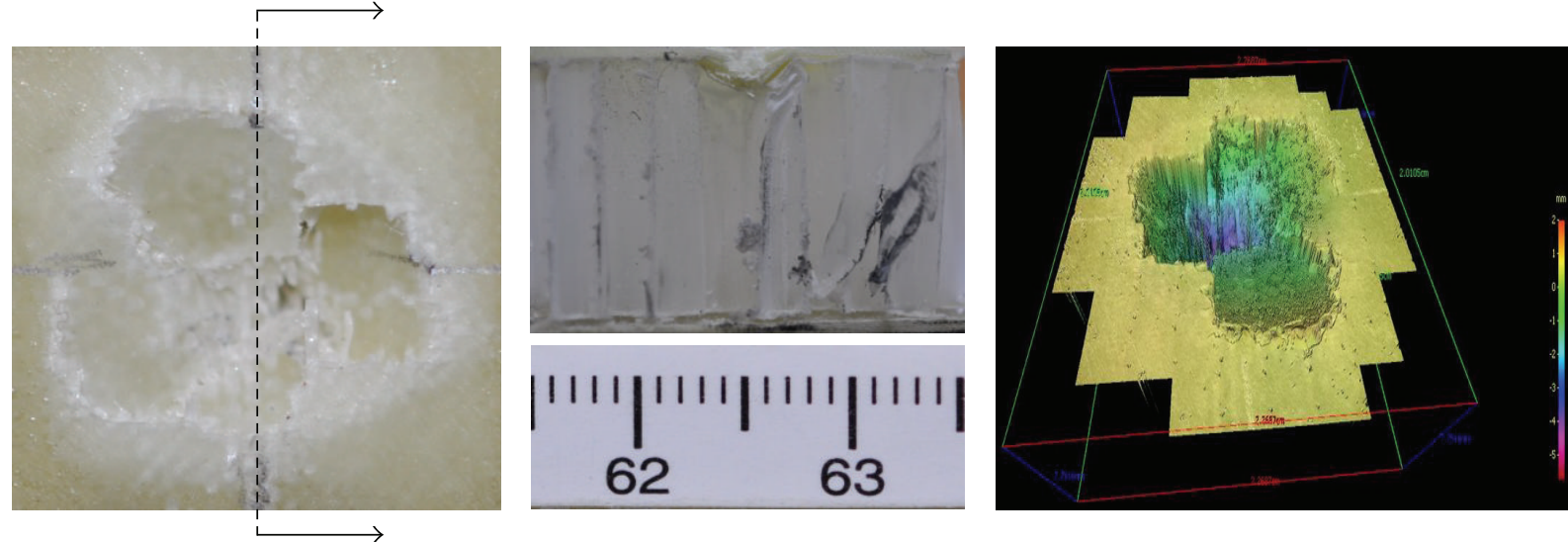

(b) Core thickness of $40 \mathrm{~mm}$
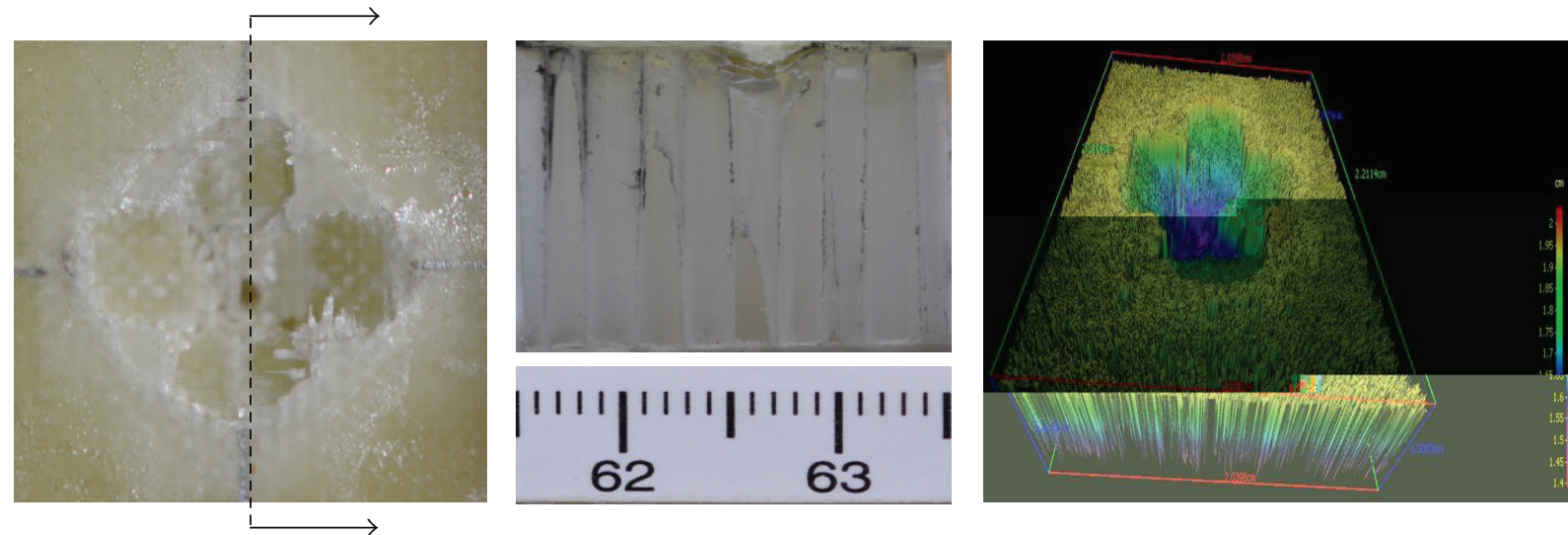

(c) Core thickness of $60 \mathrm{~mm}$

FIGURE 13: Impacted surfaces, cross-section views, and optical surface metrology of the sandwiches subjected to $45 \mathrm{~J}$ of IKE.

between the values was considerable small compared to the depth variations of the $60 \mathrm{~mm}$ honeycomb.

\section{Conclusion}

The extents of the impact response on the thermoplastic honeycomb sandwich have been investigated. The characteristics of the sandwich with three different core thicknesses were determined through energy profile diagrams and load history at different levels of impact energy. The sudden change in the gradient of the energy-time profile has indicated the initiation of the plastic deformation of the thermoplastic honeycomb due to the change in the stiffness. The thickness of the honeycomb was found to influence the extent of the damage which occurred following the low-velocity impact. Thicker core was able to sustain a higher load during core crushing before total failure occurred. The core provides higher rigidity and stability of the sandwich, which then offer higher 
TABLE 2: Average impact parameters for sandwich samples with PP honeycomb core impacted at 15, 30, and $45 \mathrm{~J}$ for core thicknesses of 20 , 40 , and $60 \mathrm{~mm}$.

\begin{tabular}{lccccc}
\hline Thickness $(\mathrm{mm})$ & Impact energy $(\mathrm{J})$ & Max. load $(\mathrm{N})$ & Total impact time $(\mathrm{ms})$ & Damage area $\left(\mathrm{cm}^{2}\right)$ & Indentation Depth $(\mathrm{mm})$ \\
\hline \multirow{2}{*}{20} & 15 & 1989.4514 & 4.00 & 1.5320 & -5.2761 \\
& 30 & 1726.7223 & 6.60 & 1.5475 & -5.3181 \\
\hline \multirow{3}{*}{40} & 45 & 1788.9875 & 6.80 & 1.5559 & -2.2511 \\
& 15 & 1597.6357 & 4.80 & 1.4773 & -4.6319 \\
& 30 & 1954.5221 & 5.20 & 2.6559 & -4.8169 \\
60 & 45 & 1673.5691 & 8.20 & 1.5667 & -5.7358 \\
& 15 & 1746.4650 & 4.00 & 1.4694 & -3.8154 \\
& 30 & 2835.3479 & 3.80 & 1.6627 & -4.4013 \\
\hline
\end{tabular}

resistance to out-of-plane deformation and may significantly influence the extent and severity of the damages following the impact. As a result, as the core thickness has been increased, higher energy absorption has been observed before failure.

\section{Acknowledgment}

The Project was supported by School of Aerospace Engineering, School of Mechanical Engineering and School of Material and Mineral Resources Engineering of Universiti Sains Malaysia under short-term grant (Grant no. 304/PBAHAN/60310001).

\section{References}

[1] S. Abrate, "Localized impact on sandwich structures with laminated facings," Applied Mechanics Reviews, vol. 50, no. 2, pp. 6982, 1997.

[2] R. A. W. Mines and N. Jones, "Approximate elastic-plastic analysis of the static and impact behaviour of polymer composite sandwich beams," Composites, vol. 26, no. 12, pp. 803-814, 1995.

[3] T. Besant, G. A. O. Davies, and D. Hitchings, "Finite element modelling of low velocity impact of composite sandwich panels," Composites Part A, vol. 32, no. 9, pp. 1189-1196, 2001.

[4] J. K. Paik, A. K. Thayamballi, and G. S. Kim, "Strength characteristics of aluminum honeycomb sandwich panels," Thin-Walled Structures, vol. 35, no. 3, pp. 205-231, 1999.

[5] J. R. Vinson, The Behaviour of Sandwich Structures of Isotropic and Composite Materials, Technomic Publishing, 1999.

[6] R. A. W. Mines, C. M. Worrall, and A. G. Gibson, "Low velocity perforation behaviour of polymer composite sandwich panels," International Journal of Impact Engineering, vol. 21, no. 10, pp. 855-879, 1998.

[7] T. Y. Reddy, H. M. Wen, S. R. Reid, and P. D. Soden, "Penetration and perforation of composite sandwich panels by hemispherical and conical projectiles," Journal of Pressure Vessel Technology, vol. 120, no. 2, pp. 186-194, 1998.

[8] H. M. Wen, T. Y. Reddy, S. R. Reid, and P. D. Soden, "Indentation, penetration and perforation of composite laminates and sandwich panels under quasi-static and projectile loading," Key Engineering Materials, no. 143, pp. 501-552, 1998.

[9] A. M. Roach, K. E. Evans, and N. Jones, “The penetration energy of sandwich panel elements under static and dynamic loading. Part I," Composite Structures, vol. 42, no. 2, pp. 119-134, 1998.
[10] A. M. Roach, N. Jones, and K. E. Evans, "The penetration energy of sandwich panel elements under static and dynamic loading. Part II," Composite Structures, vol. 42, no. 2, pp. 135-152, 1998.

[11] E. J. Herup and A. N. Palazotto, "Low-velocity impact damage initiation in graphite/epoxy/Nomex honeycomb-sandwich plates," Composites Science and Technology, vol. 57, no. 12, pp. 1581-1598, 1998.

[12] I. M. Daniel, E. E. Gdoutos, K.-A. Wang, and J. L. Abot, "Failure modes of composite sandwich beams," International Journal of Damage Mechanics, vol. 11, no. 4, pp. 309-334, 2002.

[13] R. A. W. Mines, C. M. Worrall, and A. G. Gibson, "The static and impact behaviour of polymer composite sandwich beams," Composites, vol. 25, no. 2, pp. 95-110, 1994.

[14] T. Anderson and E. Madenci, "Experimental investigation of low-velocity impact characteristics of sandwich composites," Composite Structures, vol. 50, no. 3, pp. 239-247, 2000.

[15] M. Akil Hazizan and W. J. Cantwell, "The low velocity impact response of an aluminium honeycomb sandwich structure," Composites Part B, vol. 34, no. 8, pp. 679-687, 2003.

[16] A. Petras and M. P. F. Sutcliffe, "Indentation failure analysis of sandwich beams," Composite Structures, vol. 50, no. 3, pp. 311318, 2000.

[17] D. Zenkert, "Strength of sandwich beams with mid-plane debondings in the core," Composite Structures, vol. 15, no. 4, pp. 279-299, 1990.

[18] M. Meo, R. Vignjevic, and G. Marengo, "The response of honeycomb sandwich panels under low-velocity impact loading," International Journal of Mechanical Sciences, vol. 47, no. 9, pp. 1301-1325, 2005.

[19] D. Zenkert, "Strength of sandwich beams with interface debondings," Composite Structures, vol. 17, no. 4, pp. 331-350, 1991.

[20] A. R. Othman and D. C. Barton, "Failure initiation and propagation characteristics of honeycomb sandwich composites," Composite Structures, vol. 85, no. 2, pp. 126-138, 2008.

[21] I. H. Choi, "Contact force history analysis of composite sandwich plates subjected to low-velocity impact," Composite Structures, vol. 75, no. 1-4, pp. 582-586, 2006.

[22] M. Aktaş, C. Atas, B. M. Içten, and R. Karakuzu, "An experimental investigation of the impact response of composite laminates," Composite Structures, vol. 87, no. 4, pp. 307-313, 2009. 

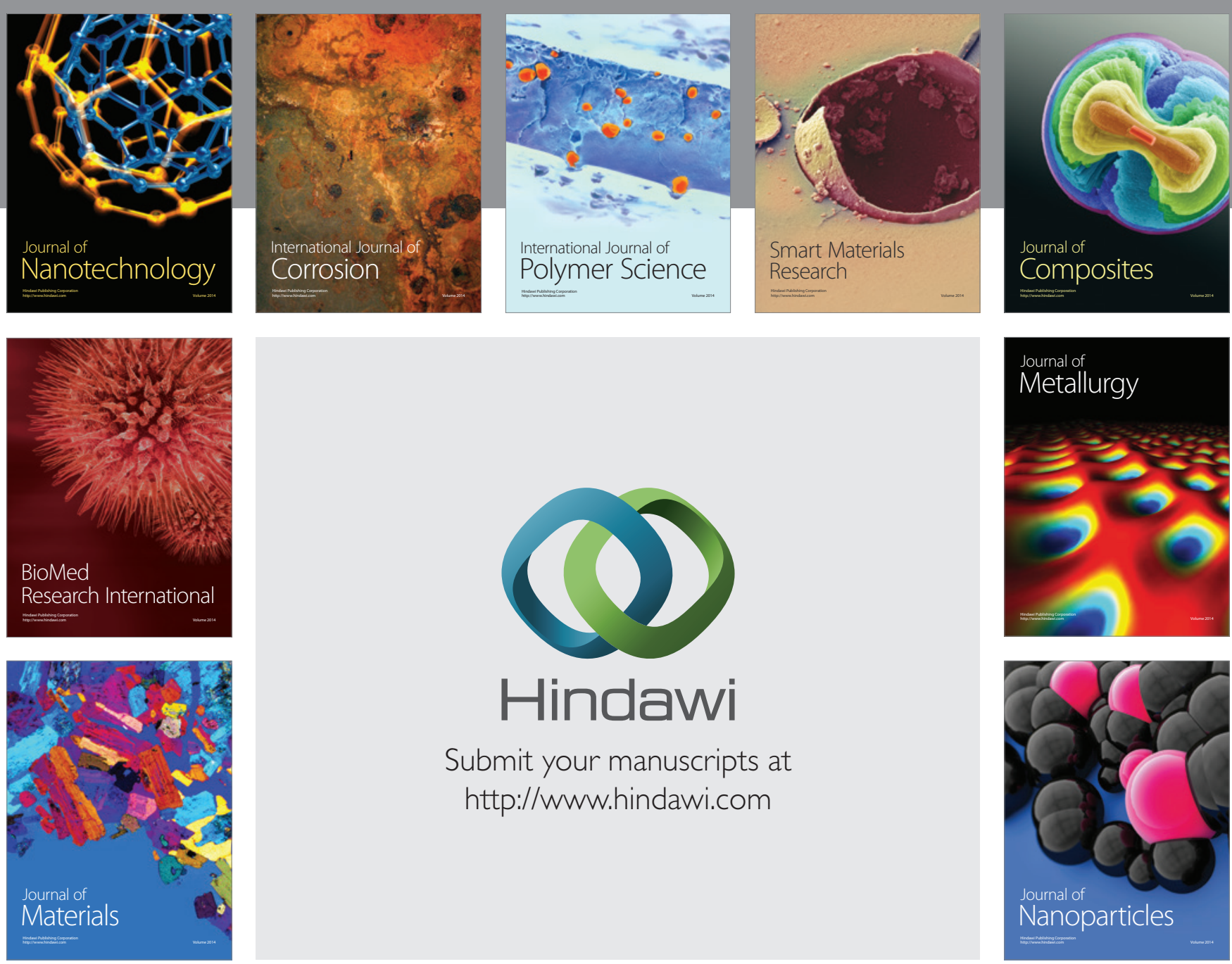

Submit your manuscripts at http://www.hindawi.com
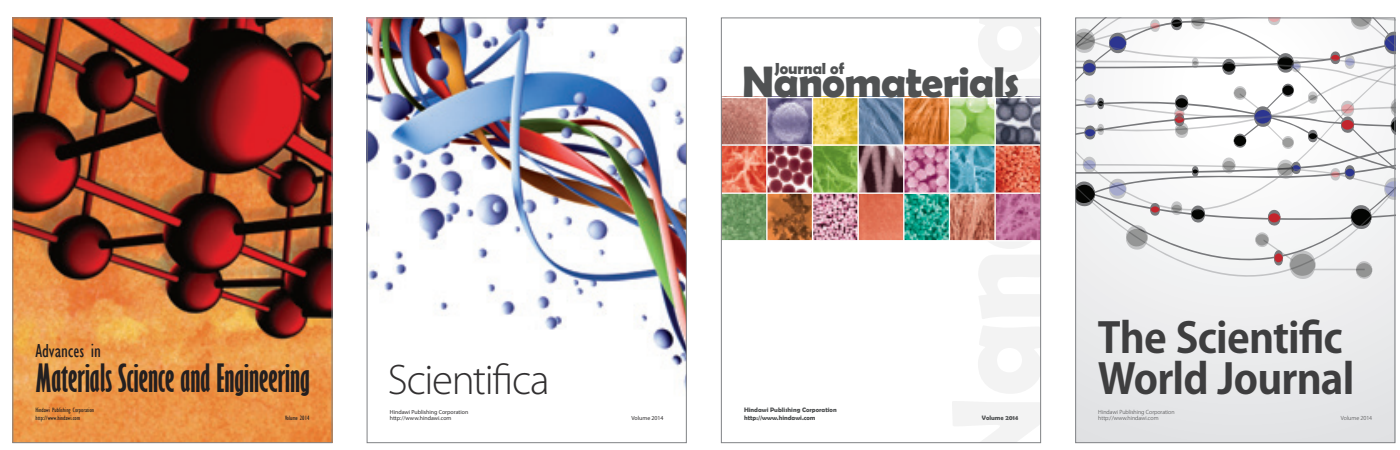

\section{The Scientific World Journal}
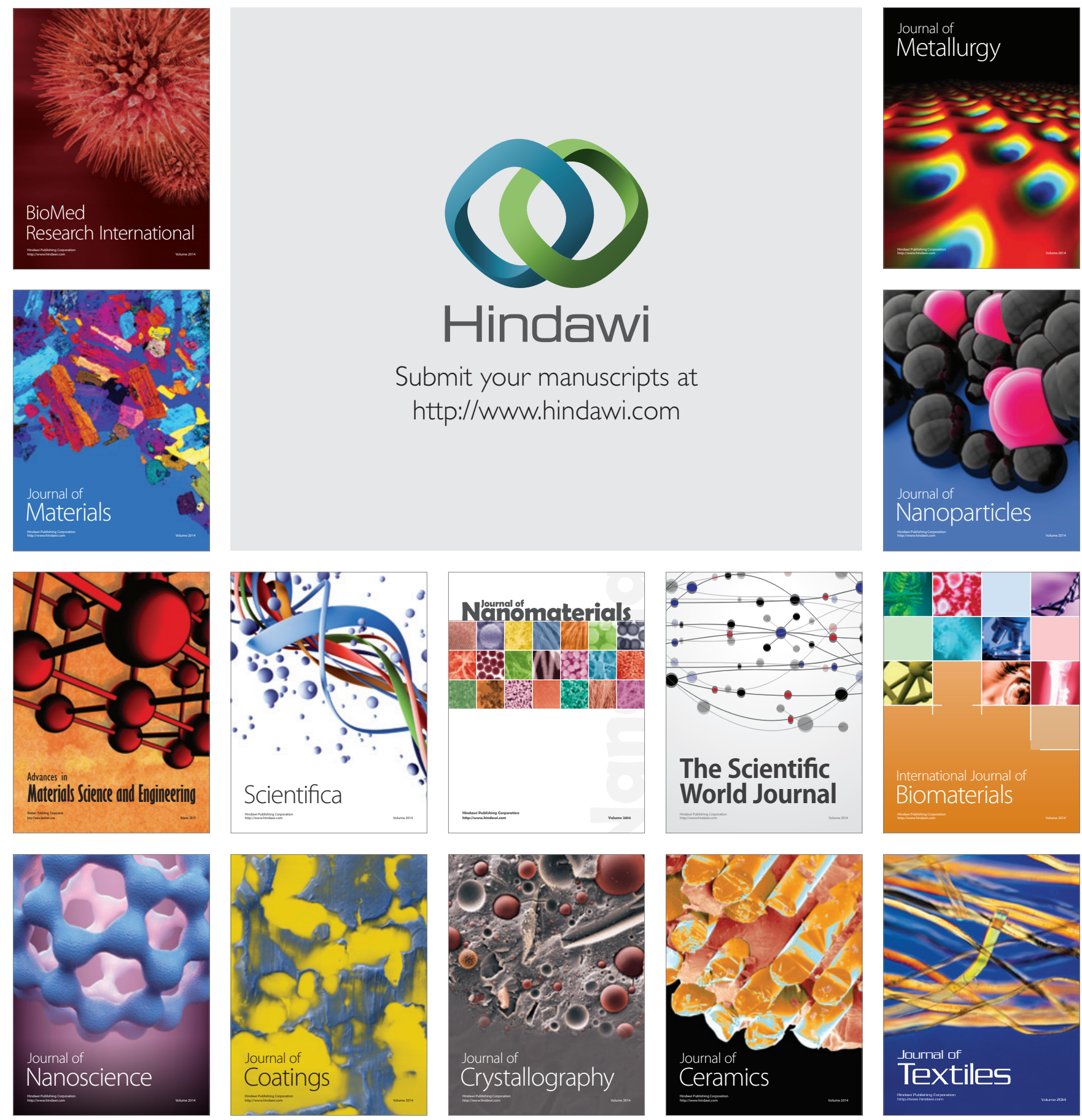